



\section{1 by Editora Artemis \\ Copyright (C) Editora Artemis \\ Copyright do Texto (C) 2021 Os autores \\ Copyright da Edição (C) 2021 Editora Artemis}

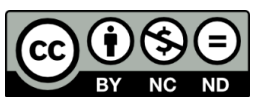

O conteúdo deste livro está licenciado sob uma Licença de Atribuição Creative Commons AtribuiçãoNão-Comercial NãoDerivativos 4.0 Internacional (CC BY-NC-ND 4.0). Direitos para esta edição cedidos à Editora Artemis pelos autores. Permitido o download da obra e o compartilhamento, desde que sejam atribuídos créditos aos autores, e sem a possibilidade de alterá-la de nenhuma forma ou utilizá-la para fins comercial. A responsabilidade pelo conteúdo dos artigos e seus dados, em sua forma, correção e confiabilidade é exclusiva dos autores. A Editora Artemis, em seu compromisso de manter e aperfeiçoar a qualidade e confiabilidade dos trabalhos que publica, conduz a avaliação cega pelos pares de todos manuscritos publicados, com base em critérios de neutralidade e imparcialidade acadêmica.

$\begin{array}{ll}\text { Editora Chefe } & \text { Profa Dra Antonella Carvalho de Oliveira } \\ \text { Editora Executiva } & \text { M.a Viviane Carvalho Mocellin } \\ \text { Direção de Arte } & \text { M.a Bruna Bejarano } \\ \text { Diagramação } & \text { Elisangela Abreu } \\ \text { Organizadora } & \text { Prof.Dr.David García Martul } \\ \text { Imagem da Capa } & \text { cienpies } \\ \text { Bibliotecário } & \text { Maurício Amormino Júnior - CRB6/2422 }\end{array}$

\section{Conselho Editorial}

Prof. a Dr.a Ada Esther Portero Ricol, Universidad Tecnológica de La Habana "José Antonio Echeverría", Cuba

Prof. Dr. Adalberto de Paula Paranhos, Universidade Federal de Uberlândia

Prof. a Dr. a Amanda Ramalho de Freitas Brito, Universidade Federal da Paraíba

Prof.a Dr.a Ana Clara Monteverde, Universidad de Buenos Aires, Argentina

Prof. Dr. Ángel Mujica Sánchez, Universidad Nacional del Altiplano, Peru

Prof. a Dr.a Angela Ester Mallmann Centenaro, Universidade do Estado de Mato Grosso

Prof.a Dr.a Begoña Blandón González, Universidad de Sevilla, Espanha

Prof. a Dr. a Carmen Pimentel, Universidade Federal Rural do Rio de Janeiro

Prof. a Dr.a Catarina Castro, Universidade Nova de Lisboa, Portugal

Prof. a Dr.a Cláudia Neves, Universidade Aberta de Portugal

Prof. Dr. Cleberton Correia Santos, Universidade Federal da Grande Dourados

Prof. Dr. David García-Martul, Universidad Carlos III de Madrid, Espanha

Prof. a Dr. a Deuzimar Costa Serra, Universidade Estadual do Maranhão

Prof.. Dr. a Eduarda Maria Rocha Teles de Castro Coelho, Universidade de Trás-os-Montes e Alto Douro, Portugal

Prof. Dr. Eduardo Eugênio Spers, Universidade de São Paulo

Prof. Dr. Eloi Martins Senhoras, Universidade Federal de Roraima

Prof. a Dr. a Elvira Laura Hernández Carballido, Universidad Autónoma del Estado de Hidalgo, México

Prof.a Dr.a Emilas Darlene Carmen Lebus, Universidad Nacional del Nordeste/ Universidad Tecnológica Nacional, Argentina

Prof. a Dr.a Erla Mariela Morales Morgado, Universidad de Salamanca, Espanha

Prof. Dr. Ernesto Cristina, Universidad de la República, Uruguay

Prof. Dr. Ernesto Ramírez-Briones, Universidad de Guadalajara, México

Prof. Dr. Gabriel Díaz Cobos, Universitat de Barcelona, Espanha

Prof. Dr. Geoffroy Roger Pointer Malpass, Universidade Federal do Triângulo Mineiro

Prof. a Dr.a Gladys Esther Leoz, Universidad Nacional de San Luis, Argentina

Prof. a Dr.a Glória Beatriz Álvarez, Universidad de Buenos Aires, Argentina

Prof. Dr. Gonçalo Poeta Fernandes, Instituto Politécnido da Guarda, Portugal

Prof. Dr. Gustavo Adolfo Juarez, Universidad Nacional de Catamarca, Argentina

Prof. a Dr. a lara Lúcia Tescarollo Dias, Universidade São Francisco

Prof. a Dr. a Isabel del Rosario Chiyon Carrasco, Universidad de Piura, Peru

Prof. a Dr. a Isabel Yohena, Universidad de Buenos Aires, Argentina

Prof. Dr. Ivan Amaro, Universidade do Estado do Rio de Janeiro

Prof. Dr. Iván Ramon Sánchez Soto, Universidad del Bío-Bío, Chile 
Prof. a Dr.a Ivânia Maria Carneiro Vieira, Universidade Federal do Amazonas

Prof. Me. Javier Antonio Albornoz, University of Miami and Miami Dade College, USA

Prof. Dr. Jesús Montero Martínez, Universidad de Castilla - La Mancha, Espanha

Prof. Dr. Joaquim Júlio Almeida Júnior, UniFIMES - Centro Universitário de Mineiros

Prof. Dr. Juan Carlos Mosquera Feijoo, Universidad Politécnica de Madrid, Espanha

Prof. Dr. Juan Diego Parra Valencia, Instituto Tecnológico Metropolitano de Medellín, Colômbia

Prof. Dr. Júlio César Ribeiro, Universidade Federal Rural do Rio de Janeiro

Prof. Dr. Leinig Antonio Perazolli, Universidade Estadual Paulista

Prof.a Dr.a Lívia do Carmo, Universidade Federal de Goiás

Prof.a Dr.a Luciane Spanhol Bordignon, Universidade de Passo Fundo

Prof. Dr. Luis Vicente Amador Muñoz, Universidad Pablo de Olavide, Espanha

Prof. a Dr.a Macarena Esteban Ibáñez, Universidad Pablo de Olavide, Espanha

Prof. Dr. Manuel Ramiro Rodriguez, Universidad Santiago de Compostela, Espanha

Prof. Dr. Marcos Augusto de Lima Nobre, Universidade Estadual Paulista

Prof. Dr. Marcos Vinicius Meiado, Universidade Federal de Sergipe

Prof. a Dr.a Mar Garrido Román, Universidad de Granada, Espanha

Prof. a Dr. a Margarida Márcia Fernandes Lima, Universidade Federal de Ouro Preto

Prof.a Dr.a Maria Aparecida José de Oliveira, Universidade Federal da Bahia

Prof. a Dr.a Maria do Céu Caetano, Universidade Nova de Lisboa, Portugal

Prof. a Dr.a Maria do Socorro Saraiva Pinheiro, Universidade Federal do Maranhão

Prof. a Dr.a Maria Lúcia Pato, Instituto Politécnico de Viseu, Portugal

Prof. a Dr. a Maritza González Moreno, Universidad Tecnológica de La Habana "José Antonio Echeverría", Cuba

Prof. a Dr.a Mauriceia Silva de Paula Vieira, Universidade Federal de Lavras

Prof. a Dr. a Odara Horta Boscolo, Universidade Federal Fluminense

Prof. - Dr. a Patrícia Vasconcelos Almeida, Universidade Federal de Lavras

Prof.a Dr. a Paula Arcoverde Cavalcanti, Universidade do Estado da Bahia

Prof. Dr. Rodrigo Marques de Almeida Guerra, Universidade Federal do Pará

Prof. Dr. Saulo Cerqueira de Aguiar Soares, Universidade Federal do Piauí

Prof. Dr. Sergio Bitencourt Araújo Barros, Universidade Federal do Piauí

Prof. Dr. Sérgio Luiz do Amaral Moretti, Universidade Federal de Uberlândia

Prof.a Dr.a Silvia Inés del Valle Navarro, Universidad Nacional de Catamarca, Argentina

Prof. a Dr.a Teresa Cardoso, Universidade Aberta de Portugal

Prof. a Dr. a Teresa Monteiro Seixas, Universidade do Porto, Portugal

Prof. Dr. Turpo Gebera Osbaldo Washington, Universidad Nacional de San Agustín de Arequipa, Peru

Prof. Dr. Valter Machado da Fonseca, Universidade Federal de Viçosa

Prof. a Dr. a Vanessa Bordin Viera, Universidade Federal de Campina Grande

Prof. a Dr. a Vera Lúcia Vasilévski dos Santos Araújo, Universidade Tecnológica Federal do Paraná

Prof. Dr. Wilson Noé Garcés Aguilar, Corporación Universitaria Autónoma del Cauca, Colômbia

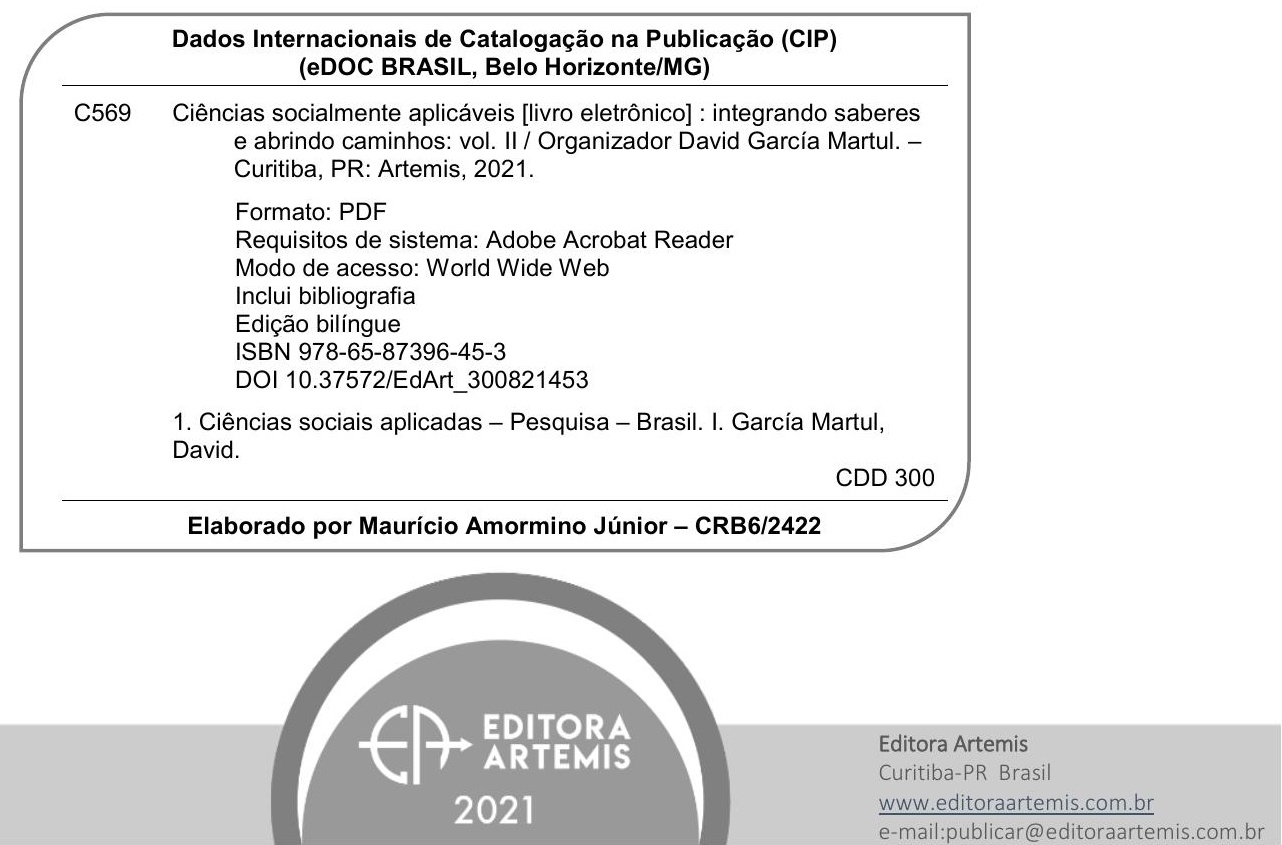




\section{PRÓLOGO - VOLUME II}

La redacción de un prólogo nunca es una tarea fácil, más aún cuando se trata de la presentación de un libro de temática interdisciplinar y transdiciplinar en el campo de las ciencias sociales aplicadas. Es interdisciplinar porque los trabajos que aquí se presentan utilizan un amplio abanico de técnicas de investigación para investigar su objeto de estudio especializado. Así es común encontrar trabajos que por la técnica empleada podríamos pensar son propios de la Antropología y la Sociología. Sin embargo, por el objeto de estudio tratado nos ha parecido más pertinente situarlo en el campo de la Comunicación. Por tanto, hemos dado relevancia al objeto de estudio frente a la metodología investigadora para determinar el campo temático de cada trabajo.

También consideramos que Ciências Socialmente Aplicáveis: Integrando Saberes e Abrindo Caminhos es un libro transdisciplinar porque los resultados de las investigaciones son aplicables a muy distintos campos del conocimiento; es decir, una investigación sobre alfabetización mediática puede muy bien ser aplicada tanto al campo de la Educación como a los campos de la Comunicación y la Sociología.

Sin embargo, previa labor de preparación de este prólogo hemos llevado a cabo una labor de análisis de contenido temático de cada uno de los trabajos aquí presentados. Su resultado ha sido un índice desarrollado por un metódico trabajo de selección de los descriptores más acordes a la temática y objeto de estudio de cada capítulo. Para la selección de los descriptores hemos seguido una herramienta, consensuada por la comunidad internacional, como es el Tesauro de la UNESCO; pues en él, se presenta de forma homogénea y normalizada la manera de designar cada uno de los campos del conocimiento. $\mathrm{Y}$ si bien debemos considerar toda herramienta de descripción como condicionada por el contexto ideológico, plasmado por sus sesgos y matices socioculturales, de la institución que lo edita pero que aporta un instrumento de navegación por las distintas materias que conforman el mapa de conocimiento de nuestro libro.

Es pues con ello que hemos procurado, de forma estructurada y sistemática, facultar al lector para introducirse en los heterogéneos contenidos del libro de una manera progresiva, armónica y lógica.

En este Volumen II se incluyen trabajos en las áreas de Políticas PúblicasGestión de Conflictos, Empresa-Marketing y Turismo. Se ha optado por el criterio de reunir materias relacionadas con el estudio del desarrollo de estrategias ligadas con actividades económicas.

En el campo de Políticas Públicas-Gestión de Conflictos incluimos ocho trabajos de investigación que tratan desde aspectos ligados con la aplicación de políticas de 
gobernanza hasta aspectos más específicos acerca de la aplicación de la gestión política en situaciones de riesgo y conflictos.

El segundo bloque de materias en este volumen es el referido a trabajos relacionados más estrictamente con las iniciativas económicas y empresariales. En este bloque vemos cómo las políticas y estrategias empleadas en la gestión del ámbito de lo público pueden ser aplicadas en iniciativas empresariales y de marketing para la creación de una plusvalía en el sector privado. En este campo contamos con un primer grupo de trabajos ligados a la gestión corporativa. En un segundo grupo veremos herramientas empleadas en la aplicación de políticas corporativas y conductas del consumidor que pueden ser de interés para la más eficaz gestión de políticas corporativas, así como algunos casos prácticos de análisis en este sentido. Finalmente incluimos trabajos acerca del marketing como producto efectivo de las políticas de gestión corporativa.

Finalmente afrontamos un tercer y último bloque de seis trabajos en el campo del Turismo como actividad económica específica, con prácticas eminentemente empresariales sin menoscabo de las implicaciones que sobre la sociedad ejerce.

Esperamos que el presente volumen de Ciências Socialmente Aplicáveis: Integrando Saberes e Abrindo Caminhos les resulten de interés pues busca proporcionar una foto fija del estado de la investigación a través de un grupo heterogéneo de trabajos aplicados y previamente evaluados sobre distintos temas comprendidos en este campo. Con ello procuramos al mismo tiempo sugerir futuras líneas de investigación a desarrollar a partir de los textos aquí publicados para todas aquellas personas ligadas a la actividad académica.

David García Martul Universidad Rey Juan Carlos 


\section{SUMÁRIO}

\section{POLITICAS PÚBLICAS E GESTÃO DE CONFLITOS}

CAPÍTULO 1

O DIÁLOGO ENTRE OS ATORES DO ESTADO E A SOCIEDADE CIVIL COMO FORÇA MOTRIZ DA GOVERNANÇA DA AML: REFLEXÕES A PARTIR DO PONTO DE VISTA DOS GOVERNOS MUNICIPAIS

João Martins de Oliveira Neto

Joaquim Manuel Croca Caeiro

Pedro Miguel Moreira da Fonseca

doil' https://doi.org/10.37572/EdArt_3008214531

CAPÍTULO 2 .

ESTUDO DE CASO DE UMA UNIDADE DE SAÚDE PÚBLICA MUNICIPAL NO INTUITO DE MELHORIA NO ATENDIMENTO A POPULAÇÃO

Priscila Marinho da Silva

doi) https://doi.org/10.37572/EdArt_3008214532

CAPÍTULO 3 38

AVALIAÇÃO E RESULTADOS DE POLÍTICAS PÚBLICAS EM FAVOR DA PRODUÇÃO NACIONAL DE JOGOS DIGITAIS

Ueli Sonderegger Matos

João Victor Boechat Gomide

Juvêncio Braga de Lima

doi) https://doi.org/10.37572/EdArt_3008214533

\section{CAPÍTULO 4}

JUSTIÇA RESTAURATIVA COMO POLÍTICA PÚBLICA MUNICIPAL DE SEGURANÇA CIDADÃ

Daniele Cristina Bahniuk Mendes

Nei Alberto Salles Filho

Thais Cristina dos Santos

doi) https://doi.org/10.37572/EdArt_3008214534 
O BENEFÍCIO DO AUXÍLIO-RECLUSÃO: REFLEXÕES CRÍTICAS SOBRE O BENEFÍCIO COMO POLITICA SOCIAL E COMO AGENTE EFETIVADOR DO PRINCÍPIO DA DIGNIDADE HUMANA

Tamara Rita Servilha Donadeli Neiva

Daniela de Figueiredo Ribeiro

doi) $h$ ttps://doi.org/10.37572/EdArt_3008214535

CAPÍTULO 6 . 86

ARBITRAJE DE CONFLICTOS Y DRAMA SOCIAL: APORTES DEL TRABAJO SOCIAL FORENSE EN SOCIEDADES DESIGUALES

Claudia Sandra Krmpotic

doi) https://doi.org/10.37572/EdArt_3008214536

CAPITULO 7 96

GESTIÓN DEL RIESGO PARTICIPATIVA COMO MEDIO HACIA LA TRANSFORMACIÓN ADAPTATIVA DE COMUNIDADES Y TERRITORIOS VULNERABLES. CASO CALETA SAN PEDRO, REGIÓN DE COQUIMBO, CHILE

Carmen Paz Castro Correa

Juan Pablo Sarmiento

Josefa Espinace

doi' https://doi.org/10.37572/EdArt_3008214537

CAPÍTULO 8 108

LA ORGANIZACIÓN DEL SOCORRO EN EL ACCIDENTE FERROVIARIO DE SANTIAGO DE COMPOSTELA

José Antonio Iglesias-Vázquez

Mario López-Pérez

Viviane Ferreira-Leite

doi' https://doi.org/10.37572/EdArt_3008214538

GESTÃO, EMPRESAS E MARKETING

CAPÍTULO 9 125

ANÁLISIS DEL ENFOQUE DE LA GERENCIA ESTRATÉGICA

Pablo Edison Ávila Ramírez

Alexandra Auxiliadora Mendoza Vera 
Gina Gabriela Loor Moreira

Martha Margarita Minaya Macías

Janeth Virginia Intriago Vera

Rubén Hernán Andrade Álvarez

Milton Geovanny Zambrano Rivera

Henrry Marcelino Pinargote Pinargote

Jhonny Antonio Ávila Ramírez

doil https://doi.org/10.37572/EdArt_3008214539

CAPÍTULO 10 141

RESPONSABILIDADE SOCIAL CORPORATIVA: INFLUÊNCIAS DO TEMA NA FORMAÇÃO EM PUBLICIDADE E PROPAGANDA

Giovana Cristina Pavei

Robson Freire

dol' https://doi.org/10.37572/EdArt_30082145310

CAPÍTULO 11 160

A GESTÃO DA MUDANÇA NO MERCADO DE TRABALHO

Maria dos Anjos Pereira

Elisete Martins

doi) https://doi.org/10.37572/EdArt_30082145311

CAPÍTULO 12

A ESCOLHA DE UMA UNIVERSIDADE VISTA SOB O PRISMA DA TEORIA DO COMPORTAMENTO DO CONSUMIDOR

Vera Lucia Telles Scaglione

Lizika Pitpar Goldchleger

doi) https://doi.org/10.37572/EdArt_30082145312

CAPÍTULO 13 186

ANÁLISIS DE LA GESTIÓN ACADÉMICA - ADMINISTRATIVA DE LA EDUCACIÓN SUPERIOR DESDE LA PERSPECTIVA DE LA ECONOMÍA POLÍTICA. CASO DE ESTUDIO: ESCUELA SUPERIOR POLITÉCNICA DE CHIMBORAZO

Carlos Benjamín Ricaurte Yépez

Grace Maribel Parra Vintimilla

Oscar Iván Granizo Paredes

José Manuel Pozo Rodríguez

doi) https://doi.org/10.37572/EdArt_30082145313 
ECONOMIAS À ESCALA E A IMPORTÂNCIA DO CAPITAL HUMANO NO SECTOR DE MOLDES EM PORTUGAL: UMA ABORDAGEM MICRO COM DADOS EM PAINEL

Fátima Diniz

Elias Soukiazis

doli) 'https://doi.org/10.37572/EdArt_30082145314

CAPÍTULO 15

OS DESAFIOS DA SUSTENTABILIDADE - DA TEORIA À PRÁTICA: O CASO PILARES DA SAÚDE

Manuel Aníbal Correia Monteiro

João Paulo Peixoto

doi) https://doi.org/10.37572/EdArt_30082145315

CAPÍTULO 16 241

RETRATOS DO MUNDO CORPORATIVO: TECENDO REFLEXÕES A PARTIR DA ANÁLISE DE FILMES

Felipe Gouvêa Pena

Juliana Oliveira Braga

Miriam de Fátima Moreira Felício Braga

doli) 'https://doi.org/10.37572/EdArt_30082145316

CAPÍTULO 17

ANÁLISE ENVOLTÓRIA DE DADOS - O MELHOR MODELO PARA ANÁLISE DE BALANÇO

Moises da Silva Martins

Rosane Aparecida Ferreira Bacha

Edilene Mayumi Murashita Takenaka

doil https://doi.org/10.37572/EdArt_30082145317

CAPÍTULO 18 266

A MORE EFFECTIVE AUDIT AFTER COSO ERM 2017 OR AFTER ISO 31000: 2009?

Alcina Augusta de Sena Portugal Dias

doi) https://doi.org/10.37572/EdArt_30082145318 
TRANSTORNO DE COMPRA COMPULSIVA (TCC): ATUALIZANDO A LITERATURA SOBRE OS COMPRADORES COMPULSIVOS SOB A ÓTICA DO COMPORTAMENTO DO CONSUMIDOR

Rafael Moreira Guimarães

doi)' https://doi.org/10.37572/EdArt_30082145319

CAPÍTULO 20. 300

RETAILBALL - UMA CHAVE PARA O SUCESSO

Maria Clara Luxo Correia

Lara Sofia Mendes Bacalhau

Nuno Fortes

doi) $h$ https://doi.org/10.37572/EdArt_30082145320

CAPÍTULO 21 .318 IMÓVEIS CORPORATIVOS NA CIDADE DE SÃO PAULO: TENDÊNCIAS DO MERCADO João da Rocha Lima Jr.

Carolina Andrea Garisto Gregório

doi) https://doi.org/10.37572/EdArt_30082145321

CAPÍTULO 22. 328

AVALIAÇÃO SOCIOECONÔMICA DE FAMÍLIAS PRODUTORAS DE MARACUJÁ BRS PÉROLA DO CERRADO RESIDENTES NO ASSENTAMENTO OZIEL ALVES III

Marco Aurélio de Carvalho Vieira e Silva

Ana Maria Costa

doi) https://doi.org/10.37572/EdArt_30082145322

CAPÍTULO 23. 346

HOME BIAS - OS CONDICIONALISMOS AO INVESTIMENTO ALÉM FRONTEIRA

Lara Sofia Mendes Bacalhau

Maria Elisabete Duarte Neves

João Soares

Rute Mendes

doij https://doi.org/10.37572/EdArt_30082145323 
RENAULT - EXPANSÃO E INTERNACIONALIZAÇÃO DA MARCA NO BRASIL

Hugo Faria

Maria Madalena Eça de Abreu

Lara Sofia Mendes Bacalhau

doi) $h$ ttps://doi.org/10.37572/EdArt_30082145324

CAPÍTULO 25.

ORGANO GOLD \& OG CARES FOUNDATION - "EVERYONE DESERVES A CHANCE", GIVE BACK - UM CASO DE MARKETING EMPRESARIAL E MARKETING SOCIAL DE MÃOS DADAS

Joana Rodrigues

Lara Sofia Mendes Bacalhau

Maria Madalena Eça de Abreu

doi) https://doi.org/10.37572/EdArt_30082145325

CAPÍTULO 26.

MARKETING DIGITAL - PASSADO, PRESENTE E FUTURO - AS TENDÊNCIAS E O CASO DA ICLIO

André Viegas

Lara Sofia Mendes Bacalhau

Maria Madalena Eça de Abreu

dol)' https://doi.org/10.37572/EdArt_30082145326

CAPÍTULO 27. 401

TIMWE - UM PARCEIRO DIGITAL DE SUCESSO NO MARKETING SOCIAL-PÚBLICO E EMPRESARIAL

Sónia Rocha

Lara Sofia Mendes Bacalhau

Maria Madalena Eça de Abreu

doi) https://doi.org/10.37572/EdArt_30082145327

CAPÍTULO 28 416

E-COMMERCE: A INFLUÊNCIA DO MARKETING DIGITAL NO COMPORTAMENTO DE CONSUMO

Carmelinda Parizzi

doi) https://doi.org/10.37572/EdArt_30082145328 
CAPÍTULO 29. 428

A CULTURA TURÍSTICA COMO MINIMIZADORA DOS IMPACTES NEGATIVOS DO TURISMO

Cecília de Melo Correia Baptista

Luís Manuel Mota dos Santos Figueira

doi) https://doi.org/10.37572/EdArt_30082145329

CAPÍTULO 30 448

EMPREENDEDORISMO RURAL E APOIO INSTITUCIONAL: O CASO DE ESTUDO DE UMA ALDEIA NO INTERIOR DE PORTUGAL

Maria Lúcia de Jesus Pato

doi) https://doi.org/10.37572/EdArt_30082145330

CAPÍTULO 31 .463

DINÂMICAS DE DESENVOLVIMENTO SUSTENTÁVEL NA SERRA DE MONTEMURO

Teresa Sequeira

doi) https://doi.org/10.37572/EdArt_30082145331

CAPÍTULO 32 482

A CARTA GASTRONÓMICA DA REGIÃO DA COMUNIDADE INTERMUNICIPAL DAS BEIRAS E SERRA DA ESTRELA COMO INSTRUMENTO PARA O DESENVOLVIMENTO DO TURISMO GASTRONÓMICO NUMA REGIÃO DO CENTRO DE PORTUGAL

Cristina Rodrigues

Adriano Costa

Anabela Sardo

doi) https://doi.org/10.37572/EdArt_30082145332

CAPÍTULO 33.

E-TURISMO: HERRAMIENTA CLAVE PARA EL DESARROLLO TURÍSTICO EN EL ECUADOR

Pablo Edison Ávila Ramírez

Alexandra Auxiliadora Mendoza Vera

Gina Gabriela Loor Moreira

Martha Margarita Minaya Macías

Janeth Virginia Intriago Vera 
Renelmo Wladimir Minaya Macías

Rocio Alexandra Mendoza Villamar

Jhonny Antonio Ávila Ramírez

Milton Geovanny Zambrano Rivera

Henrry Marcelino Pinargote Pinargote

doi)' https://doi.org/10.37572/EdArt_30082145333

CAPÍTULO 34

TURISMO SEXUAL EN MÉXICO, ENFOQUE CRIMINOLÓGICO

Martha Fabiola García-Álvarez

Luz Adriana Nápoles-Durán

Carla Monroy-Ojeda

Dante Jaime Haro-Reyes

Jorge Humberto Medina-Villarreal

doij https://doi.org/10.37572/EdArt_30082145334

SOBRE O ORGANIZADOR .526

ÍNDICE REMISSIVO 


\section{CAPÍTULO 30}

\section{EMPREENDEDORISMO RURAL E APOIO INSTITUCIONAL: O CASO DE ESTUDO DE UMA ALDEIA NO INTERIOR DE PORTUGAL ${ }^{1}$}

Data de submissão: 08/06/2021

Data de aceite: 23/06/2021

Maria Lúcia de Jesus Pato Professora Adjunta Instituto Politécnico de Viseu

Escola Superior Agrária Centro de Investigação CERNAS-IPV

Portugal https://orcid.org/0000-0002-2286-4155

RESUMO: O presente trabalho visa proporcionar uma contribuição para o conhecimento sobre a assistência e apoio institucional a iniciativas empresariais, explorando o estudo de caso de uma aldeia no interior de Portugal: Campo Benfeito na região de Montemuro. As "Capuchinhas do Montemuro" e o "Teatro Regional da Serra de Montemuro" são dois exemplos de empreendedorismo rural da aldeia que tomaram forma graças à assistência e apoio local, nomeadamente do Instituto de Assuntos Culturais e das estruturas governativas locais.

1 Este artigo constitui uma versão melhorada do estudo apresentado no Congresso ESADR 2016 com a seguinte referência: Pato, L. (2016). Rural entrepreneurship and institutional assistance: the case study of Campo Benfeito in Montemuro Region. In Maria de Fátima Oliveira \& Maria Leonor Carvalho, Book of Proceedings of ESADR 2016 Políticas Púbicas para Agricultura pós 2020 (pp. 367-383). Coimbra: Instituto Politécnico de Coimbra.
Sem esta ajuda, a aldeia estaria provavelmente num processo de agonia, como estão tantas aldeias do interior rural do país. Advoga-se que a capacidade dos atores locais em explorar tal ajuda dependeu do capital humano e social da aldeia, que mostrou ser rico em Campo Benfeito. Para a viabilidade de iniciativas como estas, sugere-se que as medidas políticas em favor do empreendedorismo (rural) devam equipar tais formas de produção a bens públicos, com o risco se tal não for feito, se perder um legado deixado pelos antepassados da aldeia.

PALAVRAS-CHAVE: Empreendedorismo rural. Apoio institucional. Governança. Região de Montemuro. Campo Benfeito. Portugal.

RURAL ENTREPRENEURSHIP AND INSTITUTIONAL ASSISTANCE: THE CASE STUDY OF A VILLAGE IN THE INTERIOR OF PORTUGAL

ABSTRACT: This work aims to provide a contribution to the knowledge about institutional assistance and support to business initiatives, exploring the case study of a village in the interior of Portugal: Campo Benfeito in the Montemuro Region. The "Capuchinhas do Montemuro" and the "Teatro Regional da Serra do Montemuro" are two examples of rural entrepreneurship in the village that took shape thanks to local assistance and support, namely from the Institute of Cultural Affairs and local government structures. Without this help, the village would probably be in a process 
of agony, as are so many villages in the rural interior of the country. It is defended that the capacity of local actors to exploit such help depended on the human and social capital of the village, which proved to be rich in Campo Benfeito. For the viability of initiatives like these, it is suggested that policy measures in favor of (rural) entrepreneurship should equate such forms of production with public goods, with the risk of losing a legacy left by the village's ancestors if this is not done.

KEYWORDS: Rural entrepreneurship. Institutional support. Governance. Região de Montemuro. Campo Benfeito. Portugal.

\section{INTRODUÇÃO}

Mercê da crise que afeta as áreas rurais, em particular o setor agrícola, muitas destas áreas têm visto as atividades agrícolas serem substituídas por empresas rurais, dando lugar a pequenas unidades de produção industrial, a atividades artesanais e de turismo e à prestação de serviços nas mais diversas áreas. Hoje em dia, estas novas atividades formam uma parte integral da dinâmica sócio-económica e, às vezes, uma fonte de emprego importante (Pato, 2020), a qual não deve ser descurada pelas entidades locais.

Por outro lado, a União Europeia (EU) tem vindo a fornecer um quadro institucional para o apoio a diversas iniciativas empresariais nas áreas rurais, ao mesmo tempo que as instituições públicas e privadas locais tem vindo a encetar esforços no sentido do desenvolvimento dessas mesmas atividades (Meccheri \& Pelloni, 2006). De acordo com os autores mencionados, tal assistência vai desde os instrumentos mais tradicionais (subsídios e apoios financeiros) para a constituição e apoio de empresas, até à assistência em aspetos de carácter mais técnico e de planeamento do negócio, tais como o acesso a modernas tecnologias, a formação da mão-de-obra, o marketing, entre outos tipos de apoio.

Apesar do reconhecimento de empreendedorismo como um dos principais determinantes do desenvolvimento econômico rural e prosperidade (Korsgaard, Müller, \& Tanvig, 2015; Pato, 2020; Pato \& Teixeira, 2016), parece existir pouca evidência empírica sobre a influência dos quadros institucionais locais na criação e desenvolvimento de empresas rurais, sobretudo em regiões mais periféricas e interiores.

Baseado numa abordagem qualitativa, o presente estudo visa assim proporcionar uma contribuição para o conhecimento sobre este assunto, explorando o estudo de caso de iniciativas empresariais numa aldeia localizada no interior de Portugal: aldeia de Campo Benfeito no concelho de Castro Daire e região de Montemuro. Na aldeia existem duas iniciativas de empreendedorismo rural, que tomaram forma graças a assistência institucional, particularmente graças à assistência/ apoio do(a): Instituto de Assuntos Culturais (ICA), da Autarquia do município e de outras entidades que se cruzaram no percurso de cada uma das iniciativas. É ainda de salientar o apoio da população local no 
processo de emergência/ desenvolvimento destas iniciativas e o espírito de comunidade que ainda se vive na aldeia (Pato, 2020). Sem esta ajuda, provavelmente a aldeia estaria num processo de agonia, como estão tantas aldeias do interior português.

O artigo inclui cinco sessões. Para além da introdução (seção 1), na seção 2 apresenta-se a revisão da literatura, nomeadamente explora-se o conceito de empreendedorismo rural e de assistência institucional. Na seção 3 apresenta-se a metodologia, com destaque para a breve descrição dos procedimentos metodológicos e da apresentação da área geográfica em estudo. Na seção 4 apresentam-se os principais resultados do trabalho desenvolvido e finalmente na seção 5 , à luz destes resultados, as reflexões finais, as limitações do estudo e pistas para trabalhos futuros.

\section{EMPREENDEDORISMO RURAL E ASSISTÊNCIA INSTITUCIONAL: EXPLORANDO OS SIGNIFICADOS}

\subsection{EMPREENDEDORISMO RURAL}

A fim de compreender a influência dos quadros institucionais locais na criação e desenvolvimento de empresas rurais, em primeiro lugar temos que desconstruir o significado do termo "empreendedorismo rural". Os esforços para definir o conceito e especificar os fatores influentes têm sido uma tarefa difícil, devido à dificuldade de definir o próprio conceito de empreendedorismo (Teixeira, 2011), mas também devido à dificuldade de observar o peso das forças e impactos da ruralidade como um meio empresarial (Stathopoulou, Psaltopoulos, \& Skuras, 2004). Na verdade, o conceito "empreendedorismo rural" conjuga dois termos também eles de difícil conceptualização: empreendedorismo e rural.

Um dos primeiros estudos que referiu o conceito foi apresentado por Wortman Jr. (1990). Neste estudo, o empreendedorismo rural é definido como "a criação de uma nova organização que introduz um novo produto, serve ou cria um novo mercado ou utiliza uma nova tecnologia num ambiente rural" (Wortman Jr., 1990, p. 330). Este conceito segue a noção de inovação apresentada por Schumpeter (1934), mas acrescenta uma dimensão nova - o espaço o rural (Pato, 2020). No entanto, o autor não desconstrui o termo, ficando igualmente por esclarecer aqui quais as implicações em termos de desenvolvimento rural (Pato, 2020).

Acontece, porém, que nas zonas rurais podem ser identificadas uma multiplicidade de processos empresariais. Enquanto alguns processos empresariais são distintamente rurais, outros simplesmente ocorrem mais ou menos de forma acidental, isto é por acaso, no espaço rural (CE, 2003; Pato \& Teixeira, 2018). 
Adicionalmente, ao passo que "o empreendedorismo rural" implica que as necessidades e o comportamento organizacional dos empresários rurais são diferentes dos das áreas urbanas (Stathopoulou et al., 2004), já que eles estão enraizados no espaço rural, outros tipos de empreendedorismo, em particular o "empreendedorismo em áreas rurais", não faz referência a tal particularidade (Baumgartner, Schulz, \& Seidl, 2013). Uma das características do empreendedor rural é a de alguém que vive numa área rural (Stathopoulou et al., 2004) e é influenciado pele rede social e traços socias desta localidade rural (Akgün, Nijkamp, Baycan, \& Brons, 2010). Para além disto, é alguém que partindo dos recursos locais, construiu o negócio com base no que a comunidade tem de mais genuíno e endógeno (Korsgaard et al., 2015). Desta forma parece consensual definir o "empreendedorismo rural" como a criação e desenvolvimento de empresas rurais, mas por gente local. A área rural não é simplesmente o espaço onde está localizada a empresa e que origina lucro, mas também o local de significado e vida social (Korsgaard et al., 2015).

Assim definido, o empreendedorismo rural vem reforçar o conceito de "desenvolvimento endógeno", onde a questão fundamental no desenvolvimento rural não é a capacidade da região para atrair empresas estrangeiras ou exógenas ao território, mas sua capacidade de gerar internamente as condições de revitalização e fortalecimento de sua própria base económico-social local (Dinis, 2006; Pato, 2020). Interesse especial deve ser dado às gentes locais, que através de uma utilização sustentável dos recursos locais, visam gerar valor para toda a comunidade rural.

\subsection{APOIO INSTITUCIONAL}

O apoio à criação de empresas é, sem dúvida, atualmente extremamente importante. Sem esta ajuda, muitas das empresas não chegariam sequer a constituirse. Tendo consciência da importância deste suporte, as instâncias europeias, o próprio governo e várias instituições a nível público e privado têm, um pouco por todo o lado, canalizado esforços no sentido de ajudar à criação de empresas em diversas áreas. Isto parece ser ainda mais importante, quanto mais desfavorecidas e periféricas forem determinadas comunidades, de que são exemplo muitas das comunidades rurais do interior de Portugal. Na verdade, geralmente as pessoas precisam de uma assistência/ apoio inicial para a constituição da empresa, até porque nessas áreas existem restrições que cerceiam o espírito empreendedor e bem assim a criação de empresas (McElwee \& Smith, 2014). Entre outros constrangimentos, pode ser mencionado o afastamento e isolamento de muitas áreas, o deficit de infraestruturas de comunicações e transportes, o insuficiente acesso ao financiamento e a pequenez dos mercados locais e globais (Smallbone, 2009). 
Ora essa assistência vai desde os instrumentos mais tradicionais (subsídios e apoios financeiros), até à assistência em aspetos de carácter mais técnico e de planeamento do negócio, tais como o acesso a modernas tecnologias, a formação da mão-de-obra, o marketing, entre outos tipos de apoio (Meccheri \& Pelloni, 2006). No entanto, as evidências sugerem que somente uma fração relativamente pequena de pessoas de áreas rurais tem sido capaz de fazer uso desses diversos instrumentos de assistência (Skuras, Meccheri, Moreira, Rosell, \& Stathopoulou, 2005). E isto porque a adoção da assistência institucional, que muitas vezes implica alguma forma de obrigação, tende a estar em contraste com o senso de independência que caracteriza muitos dos empresários rurais (Meccheri e Pelloni, 2006): "em sua casa mandam eles e não o estado", como muitas vezes apregoado pelos mesmos. Por outro lado, o débil recurso à assistência institucional por parte dos empresários rurais, tem a ver com o facto de muitos deles terem uma formação escolar e/ou académica baixa, muitas vezes apenas a obrigatória, tendo mais dificuldade em compreender processos mais formais e burocráticos de assistência (Dinis, 2011). Para estes empresários rurais, o apoio da família e parentes mais próximos é a fonte mais importante, senão a única de apoio (Winborg \& Landstrom, 2001). Neste contexto ganha força a tese de Fornahl (2003) que advoga que muitas áreas rurais são "retardatárias a nível empresarial", não apenas por causa de suas desvantagens físicas, mas também devido aos inadequados traços socioculturais do seu quadro institucional, tornando-as não-propícias para o desenvolvimento da atividade empresarial.

Tal como Meccheri e Pelloni (2006), argumenta-se aliás que a capacidade de (ou a conveniência para) as populações rurais e potenciais empresários rurais em explorar tal assistência (ou a sua incapacidade de fazê-lo), depende essencialmente do seu capital humano e do capital social das áreas rurais onde estão. Isto é, das características pessoais dos empreendedores, com particular ênfase para o conhecimento (formal e informal) e experiência para o negócio (Stathopoulou et al., 2004) e da habilidade dos atores locais em explorar as estruturas sociais locais, as parcerias e as redes (Woolcock \& Narayan, 2000).

Um excelente exemplo disso pode ser encontrado na região do Montemuro, nomeadamente na aldeia de Campo Benfeito. Na aldeia existem duas iniciativas empresariais que "deram voz à aldeia" e que tomaram forma graças ao apoio institucional de diversas entidades, nomeadamente do ICA, da autarquia local e da comunidade local. 


\section{METODOLOGIA}

\subsection{BREVE DESCRIÇÃO DOS PROCEDIMENTOS}

Tendo em conta objetivos do estudo, esta investigação tem uma natureza exploratória.

A recolha de dados foi, numa fase inicial, baseada em visitas à região e na técnica da observação. A versatilidade de observação assumiu-se como um método indispensável de recolha de informação primária e naturalmente um complemento para outros métodos de investigação, em particular das entrevistas. Com efeito, para além das entrevistas feitas junto das iniciativas empresariais em questão (Capuchinhas do Montemuro e Teatro Regional da Serra do Montemuro) foi administrado uma entrevista à população local (onde participaram três residentes locais) e ainda uma entrevista à câmara municipal de Castro Daire.

O conteúdo das entrevistas foi baseado na revisão da literatura e nos objetivos pretendidos com a investigação. A fim de identificar o discurso de cada um dos respondentes, as entrevistas foram gravadas, seguindo-se posteriormente a sua transcrição e análise de conteúdo.

\subsection{A REGIÃO EM ESTUDO}

Campo Benfeito é uma pequena aldeia da freguesia de Gosende, no concelho de Castro Daire. Geograficamente a aldeia está localizada numa encosta, contando atualmente com cerca de cinquenta residentes, cerca dos quais 14 crianças e jovens com idades inferiores aos 18 anos (informação fornecida pela população local durante a entrevista à mesma). Tal como na generalidade do concelho, as possibilidades de emprego a nível regional são débeis, tendo muitos dos habitantes da aldeia sido forçados a procurar alternativas em outros lugares.

A agricultura praticada na aldeia é uma agricultura tradicional e em alguns casos já biológica, que poderia ser aliás rentabilizada se fosse escoada para os mercados mais próximos. Não há, no entanto, a tradição de vender os excedentes agrícolas nesses mercados locais, até porque estes estão afastados da aldeia - $20 \mathrm{~km}$ (quer no caso de Castro Daire, quer no caso de Lamego), não existindo inclusive transportes públicos regulares para que tal fosse possível (Santana, 2016). Por outro lado, como referido por Santana (2016) esses produtos chegam sequer a não ser valorizados pelos habitantes da aldeia, sendo que alguma desta inércia conduz ao não aproveitamento de oportunidades e à não fixação de alguma parte da população.

De igual modo, a pecuária, sobretudo, a criação de gado bovino, ovino e caprino, o fabrico de laticínios, a produção de lã e a tecelagem de linho foram atividades 
complementares à produção vegetal, mas que se foram igualmente perdendo com o tempo (Santana, 2016).

Apesar deste cenário a aldeia de Campo Benfeito é detentora de um vasto património histórico-cultural e paisagístico. De facto, o património material e imaterial (paisagístico e histórico-cultural), permitiram-lhe a inserção na Rede de Aldeias de Portugal, em 2005 e a consequente recuperação das fachadas das casas. Igualmente importante na promoção da aldeia e de resto do próprio concelho de Castro Daire e da Região de Montemuro, são os projetos duradouros das "Capuchinhas de Montemuro" e do "Teatro Regional de Montemuro".

\section{RESULTADOS}

\subsection{A ASSISTÊNCIA DA DÉCADA DE OITENTA E NOVENTA}

É na década de oitenta, com a instalação do $\mathrm{ICA}^{2}$ na região de Montemuro, especificamente na aldeia do Mezio (concelho de Castro Daire) que os projetos de base rural que são neste estudo enfatizados se iniciaram.

O objetivo era o de lançar o projeto "Montemuro" e melhorar a qualidade de vida de dezoito aldeias rurais na "parte mais alta" do concelho, caracterizadas por uma agricultura de subsistência, uma taxa de migração elevada, uma taxa de desemprego também ela elevada (sobretudo feminina) e pela falta de condições de sanidade e saúde (Rocha, 2015).

De seguida, descreve-se em pormenor o apoio/ assistência cedida na década de oitenta e noventa aos projetos em questão.

\subsubsection{O apoio à Constituição das "Capuchinhas de Montemuro"}

O ICA trabalhava essencialmente em quatro áreas: i) saúde e ajuda aos idosos, ii) agricultura e veterinária, iii) construção (água e irrigação) e iv) emancipação e educação das mulheres (Wilson, 1988). Assim, de forma a dar vida às tradições locais e emancipar as mulheres de várias comunidades rurais do concelho de Castro Daire, entre outras iniciativas, em 1985, o ICA foi capaz de organizar algumas mulheres a trabalhar em conjunto na produção de produtos têxteis. Fê-lo através de um programa de corte e costura (com cerca de dois anos) que se realizou na aldeia de Campo Benfeito. Essas

\footnotetext{
2 O ICA é uma organização sem fins lucrativos que promove o desenvolvimento humano um pouco por todo o mundo (ICA, 2016). Esta entidade tem como objetivo atuar como uma interface para que as pessoas em uma variedade de contextos e circunstâncias sejam membros ativas das suas próprias comunidades e promovam o seu desenvolvimento pessoal e social, chamando para isso também voluntários de todo o mundo para trabalhar nas regiões mais desfavorecidas.
} 
mulheres trabalhavam a partir de matérias-primas locais, essencialmente linho e burel. Cerca de dois anos depois, seguiu-se um outro curso, no Porto, promovido pela Comissão para a Igualdade dos Direitos das Mulheres (CIDM), com cerca de seis meses. Estas mulheres iam para a grande metrópole, sem grandes expectativas, embora com um grande desejo de que a formação contribuísse para ficar na aldeia (Perdigão, 2008). Foi lá que aprenderam a valorizar a sua cultura, mas também as questões relacionadas com a parte comercial da atividade, como refere uma capuchinha durante uma das entrevistas ${ }^{3}$ :

"Foi durante este curso que começaram a preparar-nos e a perguntar-nos o que queríamos fazer, se era montar uma empresa... e aprendemos a calcular o preço dos nossos produtos (...)".

Terminado o curso no Porto, foi o regresso à aldeia. Uma das atuais Capuchinhas, por exemplo, agarrou-se à máquina de costura da mãe e começou a fazer capuchas - uma espécie de capa feita de lã que, depois de batida no pisão, fica praticamente impermeável e ainda é usada por mulheres (Perdigão, 2008). Ainda por iniciativa da CIDM começou a vir apoiá-las à aldeia uma estilista, Helena Cardoso, que se tornou num elemento fundamental para o progresso e desenvolvimento do grupo. Entretanto a câmara municipal de Castro Daire cedeu o espaço - uma escola primária vazia, onde estas mulheres decidiram começar a trabalhar com mais afinco, surgindo a empresa e a marca "Capuchinhas do Montemuro" em 1987. As então Capuchinhas terão igualmente beneficiado de uma medida do Instituto de Emprego e Formação Profissional (IEFP) para a constituição do próprio emprego a nível local.

É no final da década de oitenta e início dos anos noventa que estas mulheres vêm os seus esforços compensados, ao serem contempladas com o programa sueco "Siv Follin". O objetivo deste programa era o de apoiar mulheres em situações difíceis, mas com perspetivas de sucesso, como era o caso das "Capuchinhas do Montemuro". A estilista Helena Cardoso, agora ao serviço da "Siv Follin" passou a dedicar mais tempo ao trabalho destas mulheres, incentiva-as e valoriza-lhes o trabalho (Perdigão, 2008).

Embora o apoio da "Siv Follin" tenha terminado em 1995, o grupo manteve-se coeso e a funcionar. Por questões fiscais, em 1999 as Capuchinhas decidiram entretanto converter a constituição jurídica da empresa a cooperativa, surgindo a cooperativa "Capuchinhas do Montemuro" em 1999.

\subsubsection{O apoio à constituição do "Teatro Regional de Montemuro"}

Para além das "Capuchinhas do Montemuro", outro exemplo notável de empreendedorismo de base rural iniciado na década de oitenta existe na aldeia. O "Teatro

3 Capuchinha é o nome dado a uma mulher da cooperativa de artesanato "Capuchinhas do Montemuro". 
Regional da Serra do Montemuro" ou simplesmente "Teatro Regional de Montemuro". Os primeiros passos do teatro terão surgido no final de década de oitenta através do contato entre Graeme Pulleyn, um voluntário inglês do ICA com formação em teatro e jovens da aldeia. Em 1990 estes jovens decidiram pedir apoio ao ICA para um projeto chamado "Animar um Projeto". Neste projeto participaram cerca de 10 jovens da aldeia e Graeme seria quem estaria responsável da burocracia da iniciativa e o elo de ligação com o ICA. Além disto, estes jovens recolhiam ainda histórias junto da população mais idosa (tendo daí surgido também o Cancioneiro de Campo Benfeito).

Em 1991 este grupo decidiu avançar com a segunda edição do "Animar um projeto", sucedendo-se a este o projeto "Petra". Neste ano decidiram mais uma vez pedir apoio ao ICA. O Projeto "Petra" viajou até Lisboa e Inglaterra, tendo sido igualmente preparados e apresentados outros espetáculos.

"Lofo-Wolf" foi um desses espetáculos. Embora este espetáculo tivesse sido apresentado na Escola Secundária de Castro Daire em 1995, foi em Tondela que o trabalho destes jovens "deu o salto". O jornal Público fez uma excelente crítica ao espetáculo apresentado, começando-se a comentar inclusivamente que a companhia era realmente muito boa e que devia usufruir da assistência do estado português. Na verdade, ainda em meados dos anos noventa foi o que esta companhia fez, como nos referiu um dos responsáveis pela companhia de teatro que respondeu à entrevista:

“(...) É pá vocês com este projeto e com esta dinâmica deviam candidatar-se aos apoios do estado. Foi o que a gente fez e foi-nos logo atribuído em 95, já há vinte anos que recebemos apoio do Estado e isso deu-nos o que eu chamo a profissionalização, porque aí ficámos obrigados não só moralmente, como era até então, mas de cumprir um programa estabelecido".

E assim nasceu o Tetro regional da Serra de Montemuro. O apoio inicial do ICA foi fundamental, mas também as ligações e o apoio de Graeme, as parcerias com instituições locais/ nacionais com destaque para a Associação Cultural e Recreativa de Tondela (ACERT) e a companhia de Teatro Comuna em Lisboa e a própria câmara municipal de Castro Daire.

\subsection{A ASSISTÊNCIA POSTERIOR...}

O ICA foi fundamental no eclodir das duas iniciativas de base rural apresentadas acima. No entanto, sem o contínuo apoio e assistência às mesmas, não teriam a dimensão que têm hoje. Ao longo destas últimas duas décadas várias sido as entidades locais têm "dado a mão" e apoiado ambas as iniciativas 


\subsubsection{O apoio contínuo às "Capuchinhas do Montemuro"}

O mérito das capuchinhas foi reconhecido por uma entidade internacional que premiou o trabalho destas mulheres. Efetivamente, em 2007, fruto de uma iniciativa da Organização Internacional de Mulheres Profissionais denominada "Soroptimist International” (SI), através do Clube das Caldas da Rainha (que se deslocou à aldeia), foi feita uma candidatura do trabalho destas mulheres ao prémio internacional "Criatividade para Mulheres em Meio Rural", instituído pela "Women's World Summit Foundation", com sede em Genebra (Suíça). O prémio acabou por ser entregue pela primeira vez em Portugal às "Capuchinhas do Montemuro" (Pato, Breda, \& Figueiredo, 2015).

Importante no percurso destas mulheres tem sido também o apoio da câmara municipal de Castro Daire, como aliás proferido por uma capuchinha:

"Eles orgulham-se bastante da gente (câmara municipal ${ }^{4}$ ) e a gente quando vai a um lado e a outro sente que realmente, se pedirmos apoio para transporte, somos sempre apoiadas e estamos aqui num espaço que é deles (câmara municipal) que a gente restaurou. Mas eu penso que eles que se orgulham bastante da nossa existência e que gostam de nós... (...) e sabemos que isso também se reflete na promoção do concelho".

O discurso proferido coincide igualmente com as palavras do executivo municipal, que referiu que o município está:

“(...) sempre disponível e atento para ajudar nestas iniciativas (...) é de todo o interesse que assim seja, porque apresentam os produtos que são da nossa região, que tem a ver com a nossa cultura".

Naturalmente num concelho com características eminentemente rurais a câmara municipal tem consciência da importância e genuinidade destas iniciativas para a promoção do concelho, pedindo-lhe inclusivamente para estarem presentes em diferentes ocasiões/eventos, como referido pelo executivo municipal:

\footnotetext{
"Temos pedido a presença delas no sentido de divulgarem aquilo que é feito no nosso concelho. Estivemos presente na bolsa de turismo de Lisboa, estivemos presente na Feira Internacional Ibérica ali na Guarda e todos os eventos ligados a feiras, temos por norma chamá-las no sentido de elas divulgarem o que é nosso".
}

Embora as Capuchinhas "caminhem atualmente pelo próprio pé", na medida em que já estabeleceram um modelo de negócio e o próprio mercado, sem o apoio contínuo de várias outras entidades com influência no território (das quais as associações de desenvolvimento local), a sua sustentabilidade no tempo poderá vir a ser ameaçada. Por outro lado, dado que por força da localização e de outros constrangimentos próprios de iniciativas de empreendedorismo rural, estas não conseguem obter os resultados

${ }_{4}$ O que está em parêntesis é nosso. 
económicos que teriam se localizadas por exemplo numa metrópole urbana (como também foi referido durante a entrevista à população), este tipo de iniciativas deveria gozar de uma proteção e apoio especial. Esta questão será (de novo) levantada na parte das reflexões finais.

\subsubsection{O apoio contínuo ao "Teatro Regional de Montemuro"}

Cinco anos após o salto para o teatro profissional, o teatro de Montemuro já mostrava ser uma companhia de teatro sólida, sendo que entre 2000 e 2005 foram levadas a cabo uma série de produções que começavam a identificar esta companhia de teatro serrana (TRSM, 2016). Visível também neste percurso de cinco anos eram as parcerias que se estabeleciam com as escolas do distrito para assistiram aos espetáculos da companhia e workshops do teatro. Estes eram realizados na sala de espetáculos (“Espaço Montemuro") entretanto criada.

Com cada vez mais consistência eram também as ligações com outras companhias de teatro a nível nacional e mesmo internacional.

Com o apoio da população local, das próprias Capuchinhas e da câmara municipal de Castro Daire a companhia de teatro foi-se gradualmente afirmando na região e no país. Em 2005 a coprodução "Hotel Tomilho" do Teatro do Montemuro, uma companhia de teatro belga ("Laika") e o Centro Cultural de Belém (CCB) foi considerado um dos melhores espetáculos portugueses pelo jornal Expresso (TRSM, 2016).

Não obstante o apoio da Secretaria de Estado da Cultura no desenvolvimento da companhia, o entrevistado que respondeu à entrevista feita ao teatro, sente alguma instabilidade pelo facto de apenas poderem fazer projetos a quatro anos:

“(..) nós trabalhamos a quatro anos, neste momento, temos muitos projetos para 10 anos, mas o protocolo estabelecido com o estado é apenas de quarto anos... (...) termina em 2016. Ou seja, no próximo ano vamos formalizar uma nova candidatura para os quatro anos seguintes. E o horizonte é um bocado por aí, em termos da questão financeira é fundamental ... (...) o que me entristece e que eu pensava que era o contrário, que as coisas com o tempo estabilizavam, mas infelizmente não".

Apesar disto a Câmara Municipal tem sido fundamental no desenvolvimento da iniciativa, como a seguir se transcreve:

"Temos também com a Câmara Municipal um protocolo, que no fundo junta um conjunto de vontades (...) o Teatro do Montemuro, sendo de cá e por vocação e não só, queremos muito fazer, mostrar os nossos trabalhos aqui (...) É fundamental para nós, é onde a gente se sente bem, sem desprimor para os outros, mas a gente gosta muito de apresentar as nossas produções, e a câmara também nos proporciona isso, há um entendimento de ambas as partes". 
Tal como as Capuchinhas o Teatro do Montemuro tem-se afirmado, sendo já uma estrutura sólida e que leva o nome da Serra de Montemuro a várias partes do mundo. Por outro lado, traz também à pequena aldeia de Montemuro centenas de pessoas. Prova disso é o festival Altitudes - uma produção do teatro, que desde há mais de 20 anos se realiza durante uma semana do mês de Agosto na aldeia. Durante essa semana traz á aldeia várias companhias nacionais e internacionais e centenas de turistas que permanecem na região (Pato et al., 2015).

Para terminar este ponto, e com o intuito de levantar a questão, transcrevemse de seguida as palavras de Ana Pires, delegada regional da cultura do Centro entre Fevereiro de 1997 e Maio de 2002:

\begin{abstract}
"Com que palavras se explica que em Campo Benfeito sedie um dos grupos mais interessantes e de maior qualidade cultural do pais? Com que palavras se agradece a este gente? Com que palavras se respeita este esforço?" (Ana Pires in TRSM, 2016).
\end{abstract}

\title{
5 REFLEXÕES FINAIS
}

Os resultados deste estudo têm implicações tanto de natureza teórica como de natureza prática. Do ponto de vista teórico, as evidências decorrentes do nosso trabalho reforçam os trabalhos de outros autores (e.g, Meccheri \& Pelloni, 2006), que referem que o capital humano está de alguma forma relacionada com a adoção de assistência e apoio (financeiro ou não) para a criação e desenvolvimento destas iniciativas. Naturalmente, nos casos aqui apresentados esta assistência só terá ocorrido porque se percebeu deste o início que o património histórico-cultural existente na aldeia carecia de ser preservado e que os agentes locais eram capazes de o fazer. No caso das mulheres, sabe-se que lutaram pela sua independência económica e pelo desenvolvimento local, implicando igualmente a comunidade local em todo o processo. Com efeito, com base num input e assistência inicial, estas mulheres

\footnotetext{
"implicaram a comunidade no projeto, recorrendo aos saberes antigos das mulheres mais velhas no que diz respeito às técnicas de tecelagem e tintos; aproveitaram os teares que, sem uso, inevitavelmente apodreciam (...) aprenderam a usar as plantas e folhas das árvores para tingirem o linho e a lã, matérias-primas ecológicas, tratadas com técnicas também elas completamente ecológicas" (Perdigão, 2008, p. 15), e construíram um projeto com base nos recursos locais.
}

Da mesma forma, se há coisas que não se esperasse na década de oitenta e adiante seria ver um grupo de atores a 
"desbravar e povoar os penhascos frios, beirões e inóspitos de Campo Benfeito, no Alto da chamada Serra do Montemuro. Menos lógico seria ainda que no meio da trupe, se encontrassem atores, encenadores e dramaturgos portugueses e britânicos" (TRSM, 2016).

Do ponto de vista mais prático, advoga-se que iniciativas como estas devem ser continuamente apoiadas, não obstante muitas delas "caminharem atualmente pelo seu próprio pé”. Por um lado, é necessário que os decisores políticos e as autoridades locais tenham cada vez mais consciência do vasto património que contém os territórios rurais e das suas gentes e, formulem medidas políticas mais atentas à realidade dos mesmos territórios. Com efeito, num passado recente, as políticas institucionais rurais tendem o subestimar a importância do capital humano no desenvolvimento desses mesmos territórios rurais. Talvez porque "não compensa", são escassos nesses territórios os cursos escolares para adultos, a formação pós-escolar em diferentes áreas relacionadas com o mundo rural - artes e ofícios tradicionais, turismo, etc. Contudo é necessário ter presente que em territórios com uma população envelhecida e escassa, com uma estrutura empresarial débil e com falta de condições de vida, só se conseguirá manter a que aí resta, se forem criadas algumas oportunidades de trabalho. Como referido por Meccheri e Pelloni (2006) uma possível alternativa é providenciar esquemas de formação que contemplem o empreendedorismo rural e a criação de empresas rurais durante os cursos de formação.

Por outro lado deve-se tomar em consideração que por força da localização e circunstâncias várias, muitos destas atividades das áreas rurais devem ser equiparadas a bens públicos (Moreira, 2011). Com efeito, dadas as eventuais dificuldades de mercado, a vontade da população local e o seu espírito de iniciativa pode não ser suficiente para manter as tradições locais e a respetiva produção.

Operacionalizar esta ideia implica que para cada região rural sejam identificadas quais as atividades que baseadas nos recursos locais devem ser promovidas e merecedoras de tratamento equivalente aos bens públicos ou outra proteção semelhante (Moreira, 2011).

Este trabalho tem naturalmente limitações. Por questões de tempo não nos foi possível estender o estudo a outras comunidades locais e a outros stakeholders (empreendedores e população). Assim seria interessante estudar qual a assistência e apoio institucional dado a outros exemplos de empreendedorismo rural na própria região de Montemuro.

\section{AGRADECIMENTOS}

Este trabalho é financiado por Fundos Nacionais através da FCT - Fundação para a Ciência e a Tecnologia, I.P., no âmbito do projeto Refa UIDB/00681/2020. Agradecemos adicionalmente ao Centro de Investigação CERNAS e ao Instituto Politécnico de Viseu pelo apoio concedido. 


\section{REFERÊNCIAS BIBLIOGRÁFICAS}

AKGÜN, A. A., NIJKAMP, P., BAYCAN, T., \& BRONS, M. (2010). Embeddedness of entrepreneurs in rural areas: A comparative rough set data analysis. Tijdschrift voor Economische en Sociale Geografie, 101(5), 538-553.

BAUMGARTNER, D., SCHULZ, T., \& SEIDL, I. (2013). Quantifying entrepreneurship and its impact on local economic performance: A spatial assessment in rural Switzerland. Entrepreneurship \& Regional Development, 25(3-4), 222-250.

CE. (2003). The future of europe 's rural periphery, the role of entrepreneurship in responding to employment problems and social marginalization. Bruxeles: $C E$.

DINIS, A. (2006). Marketing and innovation: Useful tools for competitiveness in rural and peripheral areas. European Planning Studies, 14(1), 9-22.

DINIS, A. (2011). Empreendedores em meios rurais: uma tipologia a partir da perspectiva dos agentes de apoio institucional. In E. Figueiredo (Ed.), Rural Plural (pp. 397-414). Castro Verde: 100Luz.

FORNAHL, D. (2003). Entrepreneurial activities in a regional context. In D. Fornahl and T. Brenner (Eds.), Cooperation, Networks, and Institutions in Regional Innovations Systems (pp. 38-57). Edward Elgar: Cheltenham.

ICA. (2016). Our Story. Retrieved from http://www.ica-international.org/about-us/our-history/

KORSGAARD, S., MÜLLER, S., \& TANVIG, H. W. (2015). Rural entrepreneurship or entrepreneurship in the rural - between place and space. International Journal of Entrepreneurial Behavior \& Research, 21(1), 5-26.

MCELWEE, G., \& SMITH, R. (2014). Researching rural enterprise. In A. Fayolle (Ed.), Handbook of Research on Entrepreneurship (pp. 307-334). Cheltenham: Edward Elgar.

MECCHERI, N., \& PELLONI, G. (2006). Rural entrepreneurs and institutional assistance: an empirical study from mountainous Italy. Entrepreneurship and Regional Development, 18(5), 371-392.

MOREIRA, M. B. (2011). Inovação e empreendedorismo em zonas rurais desfavorecidas. In E. Figueiredo (Ed.), Rural Plural (pp. 385-396). Castro Verde: 100Luz.

PATO, M. L. (2020). Entrepreneurship and innovation towards rural development Evidence from a preripheral area in Portugal. European Countryside, 12(2), 209-220.

PATO, M. L., BREDA, Z., \& FIGUEIREDO, V. (2015). Women's entrepreneurship and local sustainability: the case study of a portuguese rural initiative. Journal of Tourism \& Development, 23, 119-128.

PATO, M. L., \& TEIXEIRA, A. A. C. (2016). Twenty years of rural entrepreneurship: a bibliometric survey. Sociologia Ruralis, 56(1), 3-28.

PATO, M. L., \& TEIXEIRA, A. A. C. (2018). Rural Entrepreneurship: the Tale of a Rare Event. Journal os Place Management and Development, 11(1), 46-59.

PERDIGÃO, T. (2008). Criatividade em meio rural Prémio entregue às Capuchinhas. Jornal de Animação da Rede Portuguesa Leader +. Pessoas e Lugares, Il Série(47), 14-15.

ROCHA, P. M. (2015). Tradução Teatral O Teatro Regional da Serra do Montemuro (Master thesis), University of Porto, Porto. 
SCHUMPETER, J. (1934). Theory of economic development: an inquiry into profits, capital, credit, interest and the business cycle. Cambridge: Havard University Press.

SKURAS, D., MECCHERI, N., MOREIRA, M. B., ROSELL, J., \& STATHOPOULOU, S. (2005). Entrepreneurial human capital accumulation and the growth of rural businesses: a four-country survey in mountainous and lagging areas of the European union. Journal of Rural Studies, 21(1), 67-79.

SMALLBONE, D. (2009). Fostering entrepreneurship in rural areas. In J. Potter and A. Hofer (Eds.), Strengthening entrepreneurship development in East Germany: lessons from local approaches (pp. 161-187). Paris: OECD.

STATHOPOULOU, S., PSALTOPOULOS, D., \& SKURAS, D. (2004). Rural entrepreneurship in Europe. A research framework and agenda. Journal of Entrepreneurial Behaviour \& Research, 10(6), 404-425.

TEIXEIRA, A. A. C. (2011). Mapping the (in)visible college(s) in the field of entrepreneurship. Scientometrics 89(1), 1-36.

TRSM. (2016). Teatro Regional da Serra do Montemuro. Retrieved from http://www. teatromontemuro.com/

WILSON, R. (1988). A pinnacle of service. The Rotarian(January), 49-50.

WINBORG, J., \& LANDSTROM, H. (2001). Financial bootstrapping in small businesses: Examining small business managers' resource acquisition behaviors. Journal of Business Venturing, 16(3), 235-254.

WOOLCOCK, M., \& NARAYAN, D. (2000). Social Capital: Implications for Development Theory, Research, and Policy. The World Bank Research Observer, 15(2), 225-249.

WORTMAN JR., M. S. (1990). Rural Entrepreneurship Research: An Integration into the Entrepreneurship Field. Agribusiness, 6(4), 329-344. 


\section{SOBRE O ORGANIZADOR}

DAVID GARCÍA MARTUL (david.martul@urjc.es) (ORCIDld: https://orcid.org/00000002-0160-9374). Profesor del Departamento de Ciencias de la Comunicación y Sociología de la Facultad de Comunicación de la Universidad Rey Juan Carlos, Madrid, España. Graduado en Historia en la Universidad de Santiago de Compostela y Graduado en Documentación en la Universidad Carlos III de Madrid. Doctor Europeo en Documentación por esta última universidad. Ha impartido docencia en numerosas universidades tanto en España, Universidad Carlos III de Madrid y Universidad Rey Juan Carlos, como en Universidades Europeas como la School of Journalism, Media and Cultural Studies de la University of Cardiff, en la University of Sheffield, la University of Brighton en Reino Unido o la HoogeSchool de Rotterdam. También ha sido docente en la Universidad de Guadalajara (México) y la UNAM. Ha participado en proyectos de investigación internacionales tanto con países europeos como africanos (con la Universidad Cheik Anta Diop y la Universidad de Cabo Verde) en el campo de la cooperación interuniversitaria para el desarrollo de herramientas de alfabetización digital. Cuenta con más de 60 trabajos de investigación científica en los campos de la Alfabetización Digital y Mediática, Documentación y Comunicación. 


\section{ÍNDICE REMISSIVO}

\section{A}

Accidente ferroviario $108,109,110$

Aluguéis corporativos 318,319

Ambiente $3,6,7,8,10,65,66,76,99,129,144,145,146,150,155,161,167,195,200,228$, $232,233,237,246,248,289,309,320,329,332,337,342,370,422,428,432,433$, $438,441,444,450,483,488,489,521$

Análise envoltória de dados 252, 253, 257, 259, 264

Antivalores 516, 519, 524

Apoio institucional 53, 448, 451, 452, 460, 461

Aptidões dos gestores 300

Arbitraje social 86, 89, 94

Atendimento ao público 19, 21, 33, 34, 37

Atualização de literatura 278

Audit 266, 267, 269, 273, 274, 276

Auxílio-reclusão $71,72,73,78,79,80,81,82,83,84,85$

B

Big data $387,388,390,391,394,395,398,399$

C

Campo Benfeito 448, 449, 452, 453, 454, 456, 459, 460, 462, 466, 471, 472, 473

Carreira 241, 242, 245, 246, 247, 250

Cidadã $64,65,66,67,68,69,70$

Cohesión social 96, 98, 99, 105, 107

Comportamento do consumidor 172, 173, 177, 178, 183, 184, 278, 287, 282, 416, 421, 422, 423, 427

Comunicación 91, 93, 104, 110, 113, 114, 134, 137, 138, 200, 503, 505, 510

Comunidade Intermunicipal das Beiras e Serra da Estrela 482, 483, 484, 489, 493

coso 128, 266, 267, 268, 269, 270, 271, 272, 273, 274, 275, 276, 277

Cultura 10, 17, 38, 39, 40, 42, 44, 45, 47, 48, 49, 50, 51, 54, 56, 57, 58, 59, 60, 61, 69, 70, $76,127,135,139,153,163,168,187,245,287,308,310,312,347,351,363,388,395,423$, $428,430,431,432,433,434,436,437,438,439,440,441,442,443,444,445,455$, $457,458,459,463,466,467,468,469,474,478,479,480,487,488,491,500,508,512$, 516,522 
Custos de informação 346, 348, 349, 350, 351, 352, 355, 360, 362

D

Dados em painel 201, 346, 354, 357

Decisiones 94, 98, 99, 125, 126, 127, 128, 130, 131, 133, 134, 135, 137, 138, 197, 503, 508

Demonstrações contábeis 252, 253, 254, 256, 260, 261, 263, 264

Desastres 98, 99, 106, 108, 109

Desenvolvimento de jogos $38,41,42,45,47,48,50,53,59,60$

Desenvolvimento local 15, 328, 334, 343, 344, 444, 457, 459, 463, 480, 501

Desenvolvimento sustentável 228, 329, 339, 408, 428, 443, 463, 468, 469, 479, 480, 488, 489

Desplazamiento $515,516,519,524$

Desporto 10, 300, 301, 302, 303, 305, 306, 307, 310, 311, 312, 313, 315, 316

Diagnóstico situacional 186

Diversidade $68,69,166,176,241,242,248,249,250,251,315,408$

$E$

E-commerce $248,416,417,418,419,424,426$

Economia da cultura 51, 439, 463, 480

Economias à escala 201

Economia social 170, 440, 463, 466, 469, 470, 478

Educación superior 186, 187, 188, 189, 190, 191, 194, 197, 198, 199, 200, 506

Empreendedorismo 184, 340, 448, 449, 450, 451, 455, 457, 460, 461, 463, 465, 466, 467, 478, 480

Empreendedorismo rural 448, 449, 450, 451, 457, 460

Empresas 38, 40, 41, 44, 49, 50, 51, 52, 53, 54, 74, 98, 126, 130, 131, 134, 135, 137, 138, $139,145,146,151,155,156,157,162,163,164,168,185,195,201,237,238,240,243,248$, $250,251,252,253,254,256,258,259,260,261,262,263,264,265,278,294,300,302$, 303, 304, 305, 306, 307, 308, 309, 310, 311, 312, 313, 322, 347, 349, 350, 351, 365, 366, $370,376,386,387,388,392,393,394,395,409,413,415,417,418,419,420,425,426$, 427, 433, 436, 438, 449, 450, 451, 460, 479, 489, 502, 503, 505, 507, 508, 510, 514

Ensino Universitário 141

ERM 2017 266, 267, 269, 270, 272, 273, 274, 275, 277

Escolha de universidade 172

Estado e sociedade civil 1, 2, 3, 5, 6, 8, 9, 12, 13, 14

Estrategia 4, 98, 105, 126, 127, 128, 130, 131, 132, 133, 136, 138, 195, 198, 503 
Estratégia de Internacionalização da Marca 365

Extensão do self 172, 173, 174, 177, 180, 182, 183

Externalidades do capital humano 201

$\mathbf{F}$

Financial frauds 266, 267

Função de produção 201, 258

Función cognoscitiva 186, 196

Funciones universitarias 186, 199

Función ideológica 186, 198

G

Games 38, 39, 40, 41, 43, 44, 45, 47, 49, 50, 51, 53, 54, 56, 57, 58, 62, 63

Gastronomia típica $483,484,487$

Gerencia 125, 126, 127, 128, 131, 135, 138, 139, 140, 190

Gestão de Equipas Empresariais-Comerciais 300

Gestão pública 10, 19, 76, 481

Gestión del riesgo 96, 99, 106

Globalización 139, 187, 189, 199, 503

Governança 1, 2, 3, 4, 5, 7, 8, 9, 10, 11, 12, 13, 14, 15, 16, 17, 250, 431, 436, 439, 446, 448, 469

Governança da AML 1, 2, 3, 4, 8, 9, 10, 11, 12, 13, 14

H

Home bias 346, 347, 349, 350, 351, 352, 353, 360, 361, 362, 363, 364

1

Imperativo tecnológico 241

Indústria criativa $38,40,57,58$

Información 109, 110, 111, 112, 113, 114, 117, 122, 123, 127, 128, 135, 136, 190, 193, 200, 503, $504,505,506,507,508,509,511,512,523$

Innovación 96, 98, 99, 100, 101, 102, 103, 105, 125, 126, 129, 139, 140, 186, 188, 200, 506, 514

Innovación social 96, 98, 99, 100, 101, 103, 105

Investimento estrangeiro 346, 347, 348, 350, 351, 352, 353, 354, 355, 360

ISO $31000266,267,272,273,274,275,277$ 
Justiça $64,65,66,67,68,69,70,74,76,80,83,163,167,469$

$\mathrm{L}$

Liderança $33,300,303,304,310,311,313,314,315,316,367,368,385,386$

M

Marketing de conteúdo 387, 391, 420

Marketing de rede $372,376,384,385,386$

Marketing digital 372, 387, 388, 390, 393, 395, 397, 398, 399, 416, 417, 419, 420, 424, 426, 427

Marketing multinivel 372, 376

Marketing público 300, 365, 372, 387, 388, 395, 397, 401

Marketing relacionado com causas 372

Marketing social $372,401,408,409,413,414$

Marketing turístico-público 387

Mercado de trabalho 160, 161, 166, 169, 248

Mercado imobiliário 319

Metodologias ativas 241, 242, 250

Mobile Marketing 387, 388, 392, 401, 402, 409, 410, 411, 414

Modelos de análise de decisão 252

Mudança 19, 53, 70, 77, 160, 161, 163, 166, 168, 169, 184, 244, 251, 310, 314, 344, 375, $388,409,445,469$

Município $9,12,13,14,19,21,23,24,34,64,67,68,69,449,457$

0

Organização 4, 5, 10, 11, 16, 26, 27, 28, 30, 31, 32, 33, 34, 48, 67, 70, 74, 142, 144, 145, 157, $160,161,162,163,164,165,167,168,169,170,174,175,227,228,229,231,232,233,234$, $237,238,239,245,256,261,294,306,311,312,313,315,330,344,372,374,412,413$, $419,420,429,431,442,446,450,454,457,468,483,485,500$

$\mathbf{P}$

Paticipação 1

Percepción social del riesgo 96, 99, 100, 102, 104, 105

Pesquisas relevantes 278 
Pilares 167, 227, 228, 229, 230, 231, 233, 239, 242, 484

Planeamento $8,9,16,227,228,229,231,232,234,235,237,238,239,314,437,438$, 439, 441, 449, 452, 486

Políticas culturais $38,40,42,44,51,56,58,468,481$

Política social 15, 71, 168, 345

Políticas públicas 1, 2, 3, 4, 5, 7, 13, 14, 15, 17, 18, 38, 40, 42, 43, 44, 47, 51, 56, 58, 62, 63, $65,67,68,69,70,72,75,76,77,78,79,84,85,92,256,294,339,340,345,431,434$, 436, 437, 440, 463, 468, 479, 518

Portugal 1, 2, 10, 15, 16, 17, 108, 161, 166, 168, 201, 202, 203, 204, 212, 223, 225, 226, 227 , 230, 232, 240, 266, 300, 314, 346, 348, 353, 354, 365, 368, 372, 375, 379, 387, 395, 401, 408, 428, 429, 430, 434, 435, 436, 437, 438, 439, 440, 442, 443, 444, 445, 446, 447, $448,449,451,454,457,461,463,464,466,470,472,473,480,481,482,483,484,485$, 486, 487, 489, 490, 499, 500

Previdência social $71,75,76,78,79,80,81,83,84$

Produtor de maracujá 328

Publicidade e Propaganda 141, 143, 144, 146, 147, 148, 152, 156, 157, 158

Q

Qualidade em saúde 19, 37

R

Região de Montemuro 448, 449, 454, 460, 477

Responsabilidade social 141, 142, 143, 144, 145, 146, 147, 148, 149, 150, 151, 152, 153, 154, 156, 157, 158, 159, 160, 162, 163, 170, 365, 366, 369, 372, 401, 408, 413, 414, 415

Responsabilidade Social Corporativa 141, 142, 143, 145, 149, 152, 157, 158, 401, 408 Restaurativa 64, 65, 67, 68, 69, 70, 89

S

Saúde 10, 19, 20, 21, 22, 23, 24, 25, 26, 27, 31, 32, 33, 37, 75, 76, 166, 169, 227, 229, 230, 231, 232, 233, 239, 240, 283, 332, 336, 342, 345, 372, 374, 376, 401, 408, 409, 412, 441, 454

Sector de moldes 201

Segurança $6,64,65,66,67,68,69,70,73,75,76,166,169,243,253,307,311,318,394$, 441, 444, 472, 488

Sexual 515, 516, 517, 518, 519, 520, 521, 522, 523, 524

Situação socioeconômica 328, 330, 331, 336 
Sociedades desiguales 86

Sudamérica 86

Sustentabilidade $2,144,147,148,150,157,227,228,229,230,231,232,233,234,235$, $238,239,240,330,428,433,437,444,457,468,478,486,497$

\section{T}

Tecnología 25, 26, 39, 45, 76, 93, 185, 187, 189, 190, 200, 201, 241, 242, 243, 244, 245, 250, 300, 307, 344, 394, 399, 409, 414, 427, 428, 433, 437, 438, 444, 450, 460, 479, 503,506

Tendências 70, 136, 191, 201, 281, 291, 318, 319, 387, 388, 390, 391, 395, 398, 400, 422, $435,446,487,488,500$

Território 2, 5, 8, 10, 12, 14, 16, 18, 26, 102, 196, 366, 411, 428, 433, 436, 437, 438, 443, $444,446,451,457,463,464,465,473,475,478,479,483,484,485,486,487,488,489$, $495,497,498,513,520$

Territórios baixa densidade 463

Trabajo Social Forense 86, 87, 90, 95

Transformación adaptativa 96

Transtorno da Compra Compulsiva 278, 294

Triaje 109

Turismo 40, 192, 200, 340, 395, 397, 398, 400, 428, 429, 430, 431, 432, 433, 434, 435, $436,437,438,439,440,441,442,443,444,445,446,447,449,457,460,468,478$, $482,483,484,485,486,487,491,497,499,500,502,503,504,505,506,507,508$, $509,510,511,512,513,514,516,519,520,523,524$

Turismo gastronómico 482, 483, 484, 485, 486, 497, 499

V

Víctima 89, 111, 114, 115, 118, 516, 517, 518, 519, 521, 522, 524 
